\title{
Potential candidate treatment agents for targeting of cholangiocarcinoma identified by gene expression profile analysis
}

\author{
SUTHIPONG CHUJAN ${ }^{1}$, TAWIT SURIYO ${ }^{2,3}$, TEERAPAT UNGTRAKUL ${ }^{4}$, \\ YOTSAWAT POMYEN ${ }^{5}$ and JUTAMAAD SATAYAVIVAD ${ }^{2,3,6}$
}

\author{
${ }^{1}$ Applied Biological Sciences Program, Chulabhorn Graduate Institute, Chulabhorn Royal Academy; ${ }^{2}$ Laboratory of \\ Pharmacology, Chulabhorn Research Institute, Bangkok 10210; ${ }^{3}$ Center of Excellence on Environmental Health and \\ Toxicology, Office of Higher Education Commission, Ministry of Education, Bangkok 10400; ${ }^{4}$ Faculty of Medicine \\ and Public Health, HRH Princess Chulabhorn College of Medical Science, Chulabhorn Royal Academy; \\ ${ }^{5}$ Translational Research Unit, Chulabhorn Research Institute; ${ }^{6}$ Environmental Toxicology Program, \\ Chulabhorn Graduate Institute, Chulabhorn Royal Academy, Bangkok 10210, Thailand
}

Received January 17, 2018; Accepted May 18, 2018

DOI: $10.3892 / \mathrm{br} .2018 .1101$

\begin{abstract}
Cholangiocarcinoma (CCA) remains to be a major health problem in several Asian countries including Thailand. The molecular mechanism of CCA is poorly understood. Early diagnosis is difficult, and at present, no effective therapeutic drug is available. The present study aimed to identify the molecular mechanism of CCA by gene expression profile analysis and to search for current approved drugs which may interact with the upregulated genes in CCA. Gene Expression Omnibus (GEO) was used to analyze the gene expression profiles of CCA patients and normal subjects. Using the Kyoto Encyclopedia of Genes and Genomes (KEGG), gene ontology enrichment analysis was also performed, with the KEGG pathway analysis indicating that pancreatic secretion, protein digestion and absorption, fat digestion and absorption, and glycerolipid metabolism may serve important roles in CCA oncogenesis. The drug signature database (DsigDB) was used to search for US Food and Drug Administration (FDA)-approved drugs potentially capable of reversing the effects of the upregulated gene expression in CCA. A total of 61 antineoplastic and 86 non-antineoplastic drugs were identified. Checkpoint kinase 1 was the most interacting with drug signatures. Many of the targeted protein inhibitors that were identified have been approved by the US-FDA as therapeutic agents for non-antineoplastic diseases, including cimetidine, valproic acid and lovastatin. The current study demonstrated an application for bioinformatics analysis in assessing the
\end{abstract}

Correspondence to: Dr Tawit Suriyo, Laboratory of Pharmacology, Chulabhorn Research Institute, 54 Kamphaeng-Phet 6 Road, Laksi, Bangkok 10210, Thailand

E-mail: tawit@cri.or.th

Key words: cholangiocarcinoma, gene expression analysis, pathway analysis, non-antineoplastic drug, gene-drug interaction potential efficacy of currently approved drugs for novel use. The present results suggest novel indications regarding existing drugs useful for CCA treatment. However, further in vitro and in vivo studies are required to support the current predictions.

\section{Introduction}

Cholangiocarcinoma (CCA) is the second most common hepatobiliary cancer after hepatocellular carcinoma and accounts for $10-15 \%$ of all liver carcinomas $(1,2)$. It arises in the biliary tract epithelium (cholangiocyte) and is categorized into three groups: Intrahepatic, perihilar and distal hepatic carcinoma. Previous studies in the US and worldwide have demonstrated that the associated mortality and incidence rates have increased since $2002(3,4)$. Clinically, CCA is a challenge to treat as patients often do not exhibit clear symptoms, making early diagnose difficult (5). At present, there is no specific molecular targeting treatment for CCA. Conventional chemotherapy is still used but is generally ineffective in cases of CCA associated with different genetic variants (6). A greater understanding of the biology of CCA may improve treatment and diagnosis.

Recent research has focused on target identification and selective inhibitors of several molecular signaling pathways (7). In earlier reports, genetic alterations were identified to be involved in CCA carcinogenesis, including point mutations in $\mathrm{p} 53$, B-Raf proto-oncogene serine/threonine kinase and V-Ki-ras2 Kirsten rat sarcoma viral oncogene homolog $(8,9)$. Liver-specific downregulation of Smad family member 4 and phosphatase and tensin homolog, as established tumor suppressor genes, may also induce CCA $(10,11)$. In addition, increased expression of cyclooxygenase-2, receptor tyrosine-protein kinase c-erbB-2 and interleukin 6 are considered to be involved in early carcinogenesis in the biliary tract epithelium $(12,13)$.

Although a variety of anticancer protein inhibitors, including Notch, Wnt, growth factor receptor and histone deacetylase inhibitors, are being developed to suppress oncoproteins, an average time of 7 years is typically required for drug approval 
following clinical trial evaluation (14). However, it has been demonstrated that certain drugs already approved by the US Food and Drug Administration (FDA) may be used to suppress cancer. For example, inhibitors of 3-hydroxy-3-methylglutaryl (HMG)-CoA reductase, including lovastatin, atorvastatin and simvastatin, and of cyclooxygenase-2 (COX-2), including celecoxib, have potential preventative effects on CCA carcinogenesis $(15,16)$. Identifying novel uses for the approved drugs also minimizes the need for toxicity studies, particularly with regard to non-antineoplastic drugs.

The study of cancer genomes, and CCA mechanisms in particular, is still in its infancy. Single gene studies are no longer feasible for this complex disease. Improved and more powerful tools for analysis by high-throughput array are required to provide greater accuracy, precision and cost-effectiveness. Gene Expression Omnibus (GEO) is a public functional genomics data repository created to aid the identification and analysis of gene regulatory and cancer signaling pathways. By also serving as a gene-drug interaction database, this may further be used to determine novel therapeutic drugs and targets that may be crucial to the identification of novel protein inhibitors.

In the present study, gene expression profiles from the GSE26566 dataset were collected to analyze differential gene expression, and currently approved drugs associated with the upregulated genes were searched in drug interaction databases. The greater availability of gene expression analytical tools and improved access to information on currently approved treatments may be useful in developing novel indications for CCA drug treatment.

\section{Materials and methods}

Data collection. The gene expression dataset of normal subjects and intrahepatic CCA (iHCCA) patients [Gene Expression Omnibus (GEO) accession no. GSE26566 (17)] were obtained from the National Center for Biotechnology Information GEO database (https://www.ncbi.nlm.nih.gov/geo/). A total of 104 cholangiocarcinoma and 6 normal intrahepatic bile duct gene expression data profiles were collected. This microarray platform (GLP6104) was collected from one type of platform: Illumina humanRef-8 v2.0 expression beadchip.

Gene expression analysis. The microarray database GLP6104 platform was analyzed using GEO2R (version 2.14.1) for the collected datasets. The data was normalized by $\log 2$ transformation in GEO2R along with the Benjamini-Hochberg procedure for false discovery rate correction. Samples were assigned to normal and cholangiocarcinoma subject groups. Following analysis by GEO2R, the dataset was displayed in terms of adjusted P-values, P-values, log fold changes, gene symbols and gene names. The top 15 most up- and downregulated genes according to most adjusted $\mathrm{P}$-value (from Student's t-test, $\mathrm{P}<0.05$ ) were selected as differentially expressed genes (DEGs).

Gene ontology $(G O)$ analysis. To investigate the DEGs at a functional level, the Database for Annotation, Visualization and Integrated Discovery (DAVID; https://david.ncifcrf.gov/) was used to establish gene clustering following GO analysis, as described previously (18). The GO was categorized into cellular component, biological process and molecular function following standard GO analysis as detailed previously (19).

Pathway analysis. The Kyoto Encyclopedia of Genes and Genomes (KEGG; http://www.genome.jp/kegg/) was accessed for assistance in investigating the dysregulated signaling pathways in cholangiocarcinoma as detailed previously (20). The DEGs were searched in the database for investigation of biochemistry pathways that may be involved in the tumorigenesis and development of cholangiocarcinoma. The up- and downregulated genes were analyzed by DAVID. The significant categories were predicted by an Expression Analysis Systematic Explorer score $<0.01$ and the minimum number of genes for the corresponding term $>2$ were considered.

Protein-protein interaction (PPI) analysis. PPI network analysis was conducted by using the search tool for the retrieval of interacting genes/proteins (STRING; http://string-db.org/) as in previous study (21). The threshold protein interaction reliability score was 0.400 , which represents a medium level of confidence (22).

Validation by The Cancer Genome Atlas (TCGA) Kaplan-Meier-plotter analysis. To confirm the analysis, an overall survival (OS) Kaplan-Meier computation was performed by using the top 30 DEGs (15 most upregulated and 15 most downregulated). Expression and OS data of the iHCCA cohort in the TCGA database was assessed and P-values obtained by log-rank test using the cBioPortal for Cancer Genomics (http://www.cbioportal.org/) (23-25).

Gene-drug interaction analysis. The drug signatures of upregulated genes and their interacting genes were identified by searching the drug signatures database for gene set analysis (DSigDB) (26). The signatures of the database are grouped into four categories: i) 1,202 FDA-approved drugs retrieved for bioactivity assay results from PubChem and ChEMBL; ii) 1,220 kinase inhibitors from human kinome profiling databases (Medical Research Council Kinase Inhibitor database and Harvard Medical School Library of Integrated Network-based Cellular Signatures database); iii) 1,309 perturbagens identified from DEGs in the three cell lines PC3 (prostate cancer), HL60 (leukemia) and SKMEL5 (melanoma) (with $>2$-fold change compared with controls); and iv) drug candidates identified by manual curation and text mining from the Therapeutics Targets Database and the Comparative Toxicogenomics Database (27-29). The drugs were further categorized according to the US-FDA database (https://www.accessdata.fda.gov/scripts/cder/daf/) as FDA-approved non-antineoplastic and neoplastic drugs.

\section{Results}

Gene expression analysis. The dataset retrieved from GEO26566 included 104 iHCCA and 6 normal profiles. The top 15 most significantly up- and downregulated genes, respectively, determined by integrative analysis in GEOR2, are listed in Table I. FYVE, RhoGEF and PH domain-containing 6 (FGD6) and chymotrypsinogen B2 (CTRB2) were the most significantly upand downregulated genes, respectively (Table I). 
Table I. Top 30 most significantly up- and downregulated differentially expressed genes.

A, Upregulated genes

\begin{tabular}{|c|c|c|c|c|}
\hline Gene probe ID & Gene symbol & Description & P-value & Log fold change \\
\hline 154240685 & FGD6 & FYVE, RhoGEF and PH domain-containing 6 & $9.58 \mathrm{E}-09$ & 3.86 \\
\hline 349501059 & CHEK1 & Checkpoint kinase 1 & $3.22 \mathrm{E}-07$ & 4.34 \\
\hline 61743966 & $C T B P 1$ & C-terminal-binding protein 1 & $3.29 \mathrm{E}-07$ & 3.63 \\
\hline 168229167 & $B U B 1 B$ & BUB 1 mitotic checkpoint serine/threonine kinase B & $6.76 \mathrm{E}-07$ & 5.38 \\
\hline 154800452 & TROAP & Trophinin-associated protein & $7.45 \mathrm{E}-07$ & 5.41 \\
\hline 157419137 & $L A M C 2$ & Laminin subunit gamma 2 & $1.57 \mathrm{E}-06$ & 4.8 \\
\hline 19882252 & CST2 & Cystatin-SA & $1.77 \mathrm{E}-06$ & 4.71 \\
\hline 748821156 & $C K A P 2 L$ & Cytoskeleton-associated protein 2-like & $2.44 \mathrm{E}-06$ & 3.93 \\
\hline 300794717 & WDHD1 & WD repeat and HMG-box DNA-binding protein 1 & $4.42 \mathrm{E}-06$ & 4.05 \\
\hline 938148819 & MMP11 & Matrix metallopeptidase 11 & $1.23 \mathrm{E}-05$ & 6.10 \\
\hline 444189305 & FAM83B & Family with sequence similarity 83 member B & $3.77 \mathrm{E}-05$ & 5.82 \\
\hline 54607054 & GJB3 & Gap junction protein beta 3 & $1.36 \mathrm{E}-04$ & 4.90 \\
\hline 148806907 & $F N D C 1$ & Fibronectin type III-domain containing 1 & $1.45 \mathrm{E}-04$ & 4.41 \\
\hline 379056370 & $C D C A 8$ & Cell division cycle-associated 8 & $1.66 \mathrm{E}-04$ & 4.01 \\
\hline 748983174 & $C N B D 2$ & Cyclic nucleotide-binding domain-containing 2 & $2.68 \mathrm{E}-04$ & 6.61 \\
\hline
\end{tabular}

B, Downregulated genes

\begin{tabular}{|c|c|c|c|c|}
\hline Gene probe ID & Gene symbol & Description & P-value & Log fold change \\
\hline 118498349 & CTRB2 & Chymotrypsinogen B2 & $8.80 \mathrm{E}-34$ & -10.15 \\
\hline 236459772 & CELA2A & Chymotrypsin-like elastase family member $2 \mathrm{~A}$ & $3.21 \mathrm{E}-29$ & -9.71 \\
\hline 54607079 & $C P B 1$ & Carboxypeptidase B1 & 9.23E-29 & -10.98 \\
\hline 38016927 & $P L A 2 G 1 B$ & Phospholipase A2 group IB & $8.53 \mathrm{E}-25$ & -10.78 \\
\hline 747165370 & CPA1 & Carboxypeptidase A1 & $1.09 \mathrm{E}-21$ & -11.95 \\
\hline 58331210 & CELA2B & Chymotrypsin-like elastase family member 2B & 3.17E-20 & -8.90 \\
\hline 440309868 & $C E L$ & Carboxyl ester lipase & $5.85 \mathrm{E}-18$ & -9.68 \\
\hline 734703929 & PNLIPRPI & Pancreatic lipase-related protein 1 & $1.14 \mathrm{E}-14$ & -8.37 \\
\hline 236460049 & CELA3A & Chymotrypsin-like elastase family member $3 \mathrm{~A}$ & $2.42 \mathrm{E}-14$ & -10.80 \\
\hline 357588512 & CLPS & Colipase & $1.88 \mathrm{E}-12$ & -12.09 \\
\hline 310923201 & PRSS1 & Protease, serine 1 & $2.48 \mathrm{E}-10$ & -11.52 \\
\hline 217416389 & CPA2 & Carboxypeptidase A2 & 3.24E-10 & -11.27 \\
\hline 62526042 & CTRC & Chymotrypsin 2 & 7.93E-09 & -10.82 \\
\hline 1010226556 & CELA3B & Chymotrypsin-like elastase family member 3B & $8.45 \mathrm{E}-07$ & -11.10 \\
\hline 1042779786 & PNLIP & Pancreatic lipase & $1.22 \mathrm{E}-06$ & -12.04 \\
\hline
\end{tabular}

Functional enrichment analysis. GO enrichment analysis of DEGs was performed for the top 30 most significant DEG signatures (15 most upregulated and 15 most downregulated). The DEGs were classified into the three GO categories of biological process, cellular component and molecular function. It was identified that the significantly enriched GO terms for biological process included proteolysis and lipid catabolic processes, while those for cellular component included extracellular space and extracellular region; the significantly enriched GO terms for molecular function included serine-type endopeptidase activity and triglyceride lipase activity (Table II).

Pathway enrichment analysis based on the KEGG database demonstrated that the DEGs were significantly enriched in
4 terms (Table III). The most significant pathway was pancreatic secretion $(\mathrm{P}=1.6 \mathrm{E}-17)$.

PPI network analysis. To investigate the associations between the DEGs and signaling pathways, a comprehensive analysis of protein interactions of the top 15 up- and downregulated genes, respectively, was conducted using the STRING database. As illustrated in Fig. 1, direct or indirect interactions were identified with the exception of 12 genes [Forkhead box p1, ADAM metallopeptidase domain 15, FGD6, sentrin-specific-peptidase 3, fermitin family member 2 , cystatin-SA, pinin, Snail family transcriptional repressor 2, fibronectin type III domain containing 1 (FNDC1), family with sequence similarity 83 member B (FAM83B), DIS3-like 3'-5' exoribonuclease 2 and gap junction 
Table II. Enriched GO categories of differentially expressed genes.

A, Biological process clustering

\begin{tabular}{llll}
\hline GO term & \multicolumn{1}{c}{ Biological process } & Gene count & \multicolumn{1}{c}{ Genes } \\
\hline GO:0006508 & Proteolysis & 11 & $\begin{array}{l}\text { CPA1, CPA2, CPB1, CTRC, CELA2A, } \\
\text { CELA2B, CELA3A, CELA3B, } \\
\end{array}$ \\
& & & CTRB2, MMP11, PRSS1 \\
GO:0007586 & Digestion & 4 & CELA3A, CTRB2, CLPS, PRSS1 \\
GO:0044241 & Lipid digestion & 3 & CEL, CLPS, PNLIP \\
GO:0022617 & Extracellular matrix & 4 & CTRB2, LAMC2, MMP11, PRSS1 \\
GO:0016042 & Lipid catabolic process & 4 & CLPS, PNLIPRP1, PNLIP, PLA2G1B \\
GO:0009235 & Cobalamin metabolic process & 3 & CTRC, CTRB2, PRSS1 \\
GO:0030299 & Intestinal cholesterol absorption & 2 & CEL, PNLIP \\
GO:0006629 & Lipid metabolic process & 3 & CEL, CLPS, PNLIPRP1 \\
GO:0007093 & Mitotic cell cycle checkpoint & 2 & BUB1B, CHEK1 \\
GO:0001523 & Retinoid metabolic process & 2 & CLPS, PNLIP \\
\hline
\end{tabular}

B, Cellular component

\begin{tabular}{llll}
\hline GO term & Biological process & Gene count & \multicolumn{1}{c}{ Genes } \\
\hline GO:0005615 & Extracellular space & 14 & $\begin{array}{l}\text { CEL, CPA1, CPA2, CPB1, CHEK1, CELA2A, 4.1E-08 } \\
\text { CELA2B, CELA3A, CELA3B, CTRB2, }\end{array}$ \\
& & & $\begin{array}{l}\text { CST2, LAMC2, PNLIPRP1, PLA2G1B } \\
\text { CEL, CPA2, CTRC, CELA2B, CTRB2, }\end{array}$ \\
GO:0005576 & Extracellular region & 13 & $\begin{array}{l}\text { CLPS, FNDC1, LAMC2, MMP11, } \\
\text { PNLIPRP1, PNLIP, PLA2G1B, PRSS1 }\end{array}$ \\
& & & BUB1B, CDCA8
\end{tabular}

C, Molecular function

\begin{tabular}{lllll}
\hline GO term & \multicolumn{1}{c}{ Biological process } & Gene count & \multicolumn{1}{c}{ Genes } \\
\hline GO:0004252 & Serine-type endopeptidase activity & 8 & CTRC, CELA2A, CELA2B, CELA3A, \\
& & & CELA3B, CTRB2, MMP11, PRSS1 \\
GO:0004806 & Triglyceride lipase activity & 3 & CEL, PNLIPRP1, PNLIP \\
GO:0004181 & Metal carboxypeptidase activity & 3 & CPA1, CPA2, CPB1 & 3.3E-04 \\
GO:0016298 & Lipase activity & 2 & CEL, PNLIPRP1 & $8.4 E-04$ \\
GO:0004180 & Carboxypeptidase activity & 2 & CPA2, CPB1 & $1.4 \mathrm{E}-02$ \\
GO:0008236 & Serine-type peptidase activity & 2 & CTRB2, PRSS1 & $2.7 \mathrm{E}-02$ \\
\hline
\end{tabular}

GO, gene ontology.

protein beta $3(G J B 3)$ ]. The associations between pathways and gene expression were categorized into 5 pathways, namely pancreatic secretion, protein digestion and absorption, lipid digestion and absorption, cell cycle and p53 signaling pathway.

Validation by TCGA Kaplan-Meier-plotter analysis. For validation of altered gene signatures using clinical data, CCA data was retrieved from the TCGA database $(n=36)$. Cases were divided into those with alterations in the previously identified DEGs ( $n=20)$ and those without (13). The Kaplan-Meier curve demonstrated that the altered genes group was associated with a significantly lower survival rate ( $\mathrm{P}=0.0947$; Fig. 2).
Assessment of gene-drug interaction. Drug signatures from drug-upregulated gene interactions in DsigDB were classified, based on known FDA-approved targeted agents including neoplastic and non-neoplastic drugs. A total of 86 non-neoplastic and 61 neoplastic drugs were identified. Among the top upregulated genes, CHEK1 was the most interacting with drug signatures. No drug signatures were identified for CST2, MMP11 or cyclic nucleotide binding domain-containing 2 (Table IV). The interacting anticancer drugs belonged to 6 categories in the FDA database, namely alkylating agent, hormone agent, cytotoxic alkaloid, antitumor antibiotic, antimetabolite and protein inhibitor (Table V). 
Table III. Enriched Kyoto Encyclopedia of Genes and Genomes pathways of differentially expressed genes.

\begin{tabular}{|c|c|c|c|c|}
\hline Term & Pathway & P-value & Gene count & Genes \\
\hline Hsa:04972 & Pancreatic secretion & $1.6 \mathrm{E}-17$ & 12 & $\begin{array}{l}\text { CEL, CPA1, CPA2, CPB1, CELA2A, } \\
\text { CELA2B, CELA3A, CELA3B, PNLIPRP1, } \\
\text { PNLIP, PLA2G1B, PRSS1 }\end{array}$ \\
\hline Hsa:04972 & Protein digestion and absorption & 7.5E-10 & 8 & $\begin{array}{l}\text { CPA1, CPA2, CPB1, CELA2A, CELA2B, } \\
\text { CELA3A, CELA3B, PRSS1 }\end{array}$ \\
\hline Hsa:04975 & Fat digestion and absorption & $2.0 \mathrm{E}-06$ & 5 & CEL, CLPS, PNLIPRPI I PNLIP, PLA2G1B \\
\hline Hsa:00561 & Glycerolipid metabolism & $8.7 \mathrm{E}-03$ & 3 & CEL, PNLIPRP1, PNLIP \\
\hline
\end{tabular}

Hsa, Homo sapiens.

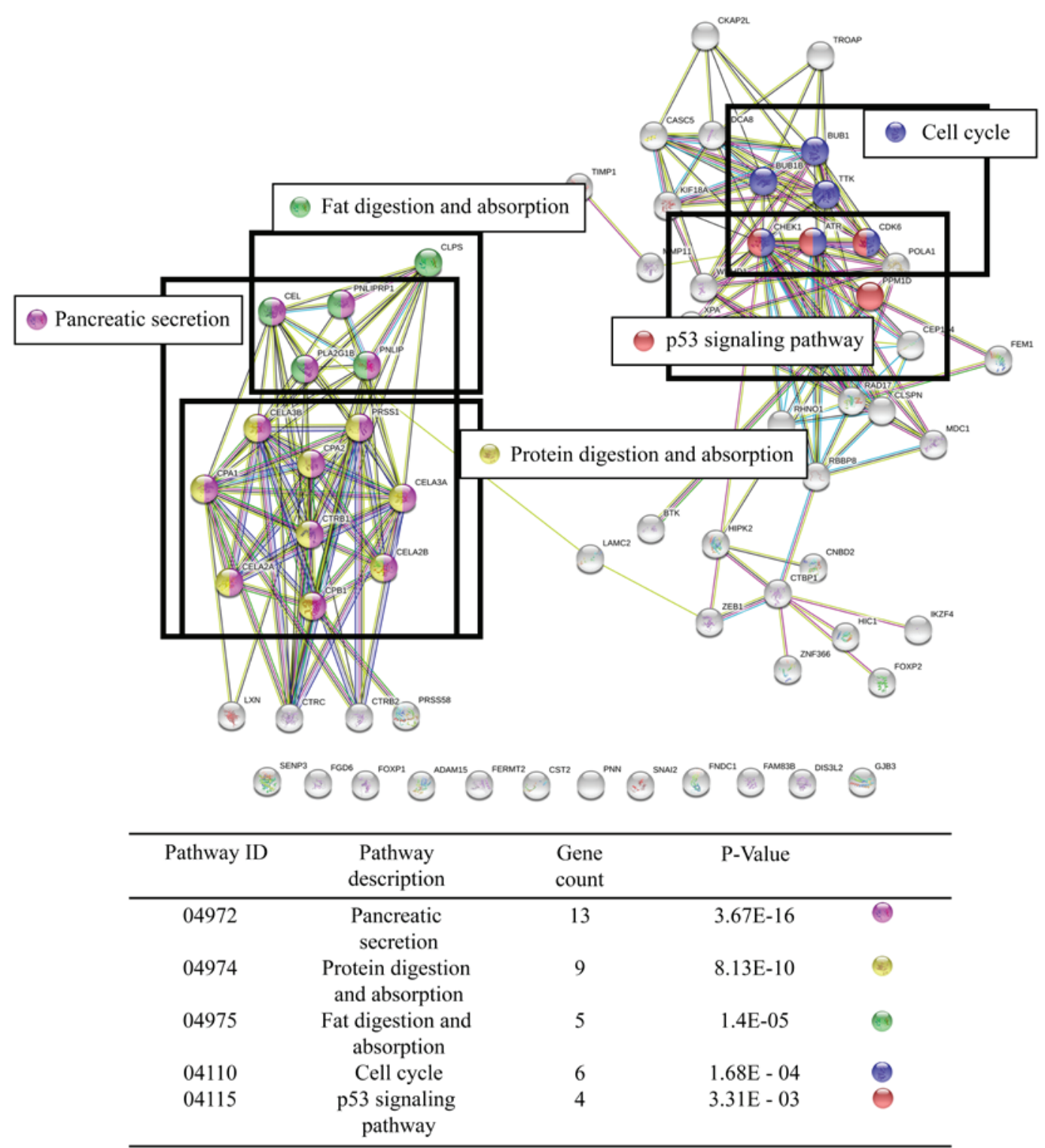

Figure 1. Protein-protein interaction network for differentially expressed genes. The genes with no direct interaction with any other partner are the co-expression genes of the genes of interest.

\section{Discussion}

Although previous study has suggested numerous biomarkers and therapeutic targets for CCA (30), there remains to be few treatments and drugs available to overcome the disease. In addition, the molecular mechanisms of CCA are not fully 


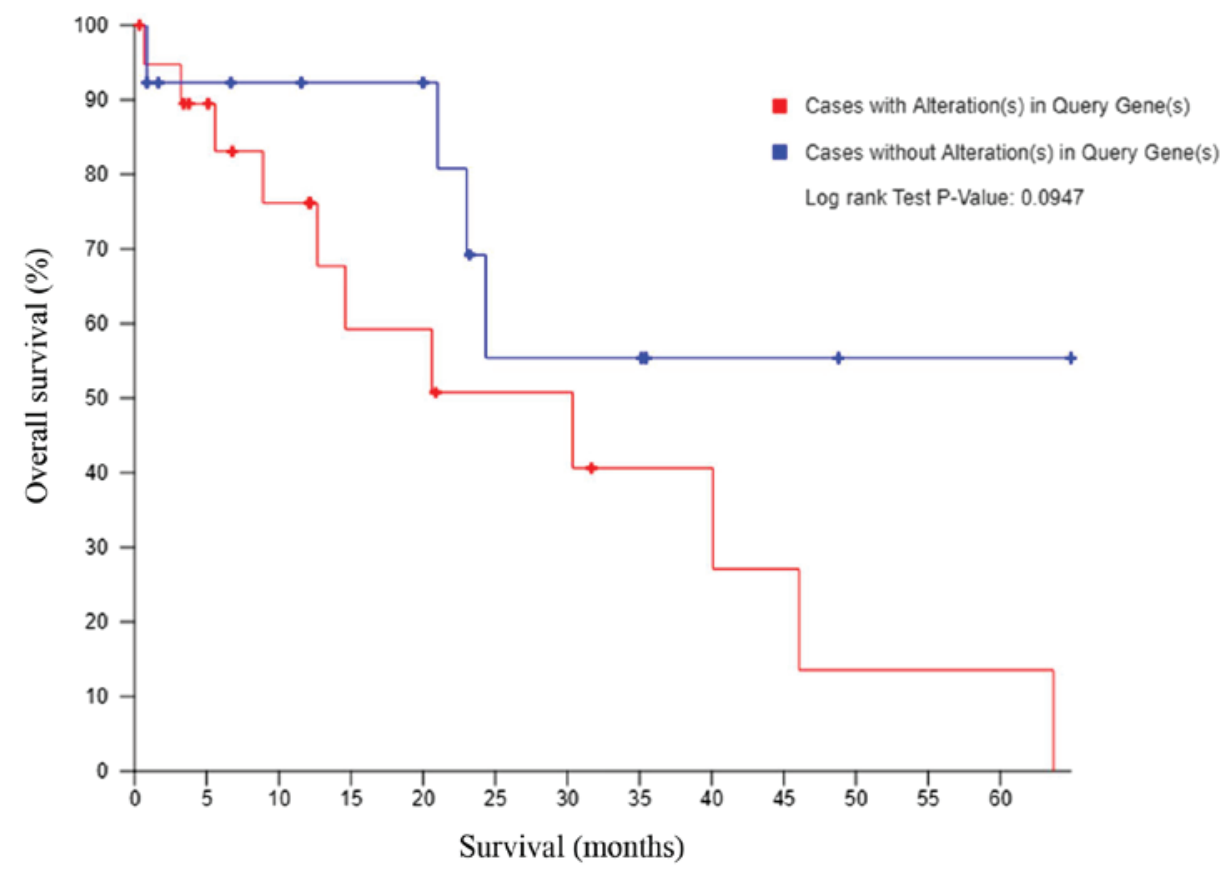

\begin{tabular}{|c|c|c|c|c|}
\hline & $\begin{array}{l}\text { Number of } \\
\text { cases, total }\end{array}$ & $\begin{array}{c}\text { Number of cases, } \\
\text { deceased }\end{array}$ & $\begin{array}{l}\text { Median survival, } \\
\text { months }\end{array}$ & $\mathrm{P}$-value \\
\hline \multirow{2}{*}{$\begin{array}{l}\text { Cases with alterations } \\
\text { in query genes }\end{array}$} & 20 & 11 & 30.35 & \\
\hline & & & & 0.0947 \\
\hline $\begin{array}{l}\text { Cases without } \\
\text { alterations in query } \\
\text { genes }\end{array}$ & 13 & 4 & NA & \\
\hline
\end{tabular}

Figure 2. Kaplan-Meier survival curves for the association between the gene alteration of differentially expressed genes and the overall survival time of patients with cholangiocarcinoma.

understood. In the present study, gene expression profiles and dysregulated pathways of CCA were analyzed, along with gene-drug interactions for drug repositioning.

In the present study, gene expression analysis was performed on a CCA patient dataset. The analysis firstly determined the top 30 DEGs that may be important for CCA carcinogenesis. Checkpoint kinase 1 (CHEK1) is required for DNA replication and cell survival in cancer (31). BUB1 mitotic checkpoint serine/threonine kinase B (BUB1B) and cell division cycle-associated 8 (CDCA8) have been identified to be involved in cell division and the cell spindle check-point. Increased expression in progressive cholangiocarcinoma has also been identified (32-34). A previous study observed that matrix metalloproteinase 11 (MMP11) was upregulated in CCA patients with poor prognosis. Therefore, MMP11 may be useful as a prognostic marker in CCA (35-36).

GO and KEGG pathway analysis demonstrated that the main biological processes involved in CCA were extracellular matrix and protein and lipid metabolism. A previous study of bile acid identified downregulated genes including CTRB, colipase, chymotrypsin-like elastase family member $3 \mathrm{~A}(C E L A 3 A)$ and $C E L A 3 B$, phospholipase A2, chymotrypsin 2, carboxypepti- dase $\mathrm{B}(C P B)$ and $\mathrm{CPA}$, similar to the present gene expression analysis. The profiles of these genes also differ markedly between CCA patients and normal subjects, and they may be protein markers for differentiating malignant from benign tumors (37). Integrative analysis of five microarrays in the GSE26566 dataset indicated that MMP11 and FGD6 were upregulated while $C E L A 2 A$ and $C T R B 2$ were downregulated. These genes were associated with the extracellular matrix, cell division processes, bile acid secretion and protein and lipid metabolism, with these biological processes implicated in various pathways in CCA progression (38). These results of DEG pathway analysis may be used to investigate and target the mechanism of disease initiation, to ultimately treat CCA, and to clarify the association between metabolic dysregulation and CCA progression.

Previous PPI analysis revealed an association of ataxia telangiectasia with $\operatorname{Rad} 3$-related protein/casein kinase 1 signaling in p53 activation, which serves an important role in DNA repair, cell division and the cell cycle (39-40). CTRB, a member of a family of serine proteases, is secreted into the gastrointestinal tract and activated through proteolytic cleavage by protease, serine 1 . A previous study observed low-level expression of CTRB in pancreatic cancer (41). The 
Table IV. Non-neoplastic and neoplastic drugs relating to upregulated genes in cholangiocarcinoma.

Gene symbol Total drugs Non-neoplastic drugs Neoplastic drugs

\begin{tabular}{|c|c|c|c|}
\hline FGD6 & 8 & Zalcitabine, digoxin, raloxifene, retinoic acid & Vorinostat, tamoxifen, 5-fluorouracil, melphalan \\
\hline CHEK1 & 44 & $\begin{array}{l}\text { Chlorzoxazone, dirithromycin, medrysone, } \\
\text { latamoxef, clindamycin, ipratropium bromide, } \\
\text { danazol, thymidine, caffeine, mucosolvan, } \\
\text { lovastatin, troglitazone, rimonabant } \\
\text { hydrochloride, menadione, retinoic acid, } \\
\text { diclofenac, carbamazepine, valproic acid, }\end{array}$ & $\begin{array}{l}\text { Etoposide, bosutinib, sunitinib, daunorubicin, } \\
\text { irinotecan, bortezomib, melphalan, mitomycin } \\
\text { vorinostat, hydroxyurea, olaparib, 5-fluorouracil } \\
\text { gemcitabine, temozolomide, doxorubicin, } \\
\text { decitabine, carmustine, bortezomib, } \\
\text { fludarabine, irinotecan, clofarabine, busalfan }\end{array}$ \\
\hline
\end{tabular}

CTBP1 18 Nifedipine, clofazimine, chlortetracycline, Vorinostat chlozoxazone, baclofen, levonorgestrel, cimetidine, ambroxol, medrysone, valproic acid, dorzolamide, clindamycin, ipratropium bromide, danazole, niclozamide, vitamin E, acetaminophen

$B U B 1 B$

Ciclopirox, trifluridine, pyrvinium,

clindamycin, colchicine, piroxicam, acetaminophen, valproic acid

\begin{tabular}{|c|c|c|}
\hline TROAP & 11 & $\begin{array}{l}\text { Ciclopirox, trifluridine, pergolide, } \\
\text { acetaminophen, valproic acid }\end{array}$ \\
\hline$L A M C 2$ & 4 & Valproic acid, mifepristone \\
\hline CST2 & 0 & - \\
\hline$C K A P 2 L$ & 3 & Retinoic acid, acetaminophen \\
\hline WDHDI & 10 & $\begin{array}{l}\text { Zalcitabine, primaquine, doxycycline, } \\
\text { latamoxef, cianidanol, retinoic acid, } \\
\text { acetaminophen, valproic acid }\end{array}$ \\
\hline$M M P 11$ & 0 & - \\
\hline FAM83B & 1 & Valproic acid \\
\hline$J G B 3$ & 5 & Retigabine \\
\hline FNDC1 & 1 & Valproic acid \\
\hline CDCA8 & 22 & $\begin{array}{l}\text { Chlortetracycline, chlorzoxazone, ciclopirox, } \\
\text { trifluridine, cimetidine, medrysone, pyrvinium, } \\
\text { latamoxef, glibenclamide, metronidazole, } \\
\text { monobenzone, piroxicam, retinoic acid, } \\
\text { acetaminophen, zidovudine }\end{array}$ \\
\hline
\end{tabular}

CNBD2 147
86
Daunorubicin, etoposide, azacitidine, irinotecan, fulvestrant, docetaxel, dasatinib, decitabine, doxorubicin, 5-fluorouracil, paclitaxel, bicalutamide

Etoposide, azacitidine, methotrexate, doxorubicin, irinotecan, 5-fluorouracil

Mechlorethamine, cyclophosphamide

Dasatinib

Dasatinib, vorinostat

Vorinostat, azacitidine, doxorubicin, decitabine

Azacitidine, methotrexate, doxorubicin, irinotecan, 5-fluorouracil, vinblastine, cytarabine current analysis of CCA patient profiles revealed similar results. As concluded previously (41), this suggests that CTRB may be a genetic marker for CCA. Furthermore, since genes including carboxyl ester lipase, pancreatic lipase-related protein 1, pancreatic lipase and phospholipase A2 group IB associated with pancreatic secretion and fat digestion and absorption exhibited significant interaction, the tumorigenesis and progression of CCA may lead to the dysfunction of liver metabolism and disruption of pancreatic function.

According to the survival analysis, patients with CCA in the altered gene group had a lower rate of OS compared with those patients with no alterations in the DEGs of interest. Genetic alterations in cell metabolism may contribute to poor prognosis in human cancers (42). Lipid metabolism is now considered to have a key role in cancer progression; it has been proposed that increased metabolic flux may serve as substrate source for phospholipid synthesis in the rapid growth stages of cancer (43).

The use of molecular signatures in cancer to determine potential drug therapies is a widespread technique (44). Potential drugs that target molecular aberrations in various CCA pathways have been proposed (45). In the present study, the genetic signatures of upregulated genes from microarray datasets were analyzed for gene-drug interactions, and US-FDA-approved drugs were grouped according to their FDA classification as antineoplastic and non-antineoplastic agents. The present study demonstrated the potential of various FDA approved antineoplastic drugs for use in CCA treatment. For example, vorinostat is a histone deacetylase inhibitor which has been approved by the FDA for the treatment of cutaneous 
Table V. Categories of the US Food and Drug Administration-approved drugs associated with upregulated genes.

\begin{tabular}{ll} 
Category & \multicolumn{1}{c}{ Drug name } \\
\hline Alkylating agent & $\begin{array}{l}\text { Melphalan, temozolomide, busalfan, carmustine, mechlorethamine, } \\
\text { cyclophosphamide, busalfan } \\
\text { Tamoxifen, fulvestrant, bicalutamide } \\
\text { Etoposide, irinotecan, vinblastine, docetaxel, paclitaxel } \\
\text { Cytotoxic alkaloid }\end{array}$ \\
$\begin{array}{l}\text { Antitumor antibiotic } \\
\text { Antimetabolite }\end{array}$ & $\begin{array}{l}\text { Methotrexate, 5-fluorouracil, clofarabine, gemcitabine, cytarabine, } \\
\text { azacitidine, fludarabine, decitabine, hydroxyurea }\end{array}$ \\
Protein inhibitor & Vorinostat, bosutinib, sunitinib, bortezomib, olaparib
\end{tabular}

manifestations of cutaneous T-cell lymphoma; olaparib is a poly-ADP-ribose polymerase inhibitor approved for ovarian and breast cancer treatment; and sunitinib, a multitargeted receptor tyrosine kinase inhibitor, has been approved by the FDA for the treatment of renal cell carcinoma (46-48). Also dasatinib, a kinase inhibitor approved for use in patients with chronic myelogenous leukemia, may be used to treat CCA by targeting the FGD6, CHEK1, C-terminal binding protein 1 $(C T B P 1)$, cytoskeleton-associated protein 2-like and WD repeat and HMG-box DNA-binding protein 1 (WDHD1) genes. Sunitinib has been reported to have possible use in iHCCA chemotherapies, where resistance is an issue in advanced stage patients (49-51).

Several chemotherapeutic drugs may be used to treat bile duct cancer, for example, 5-fluorouracil, gemcitabine, cisplatin, capecitabine and oxaliplatin. The current standard treatment drugs for CCA are 5-fluorouracil, gemcitabine, or their combinations with cisplatin. In certain cases, two or more of these drugs may be combined. However, their treatment efficacy is unsatisfactory with low clinical response rate (52). A previous study observed survival of patients treated with cisplatin plus gemcitabine, there may be little benefit to patients because of the debilitating side effects, depending on the amount and frequency of the dosage $(53,54)$. Nonetheless, CCA is a heterogeneous cancer involving multifactorial risks $(55,56)$. The present results demonstrate that the other antineoplastic drugs, including protein inhibitors such as vorinostat, sunitinib and olaparib, and standard chemotherapy drugs such as melphalan, etoposide, and mitomycin, may be suitable candidates for drug repositioning for CCA and should be studied further.

The approach of the current study was to investigate established drugs to identify novel indications for cancer treatment. The results indicated that non-antineoplastic agents interacted with certain genes implicated in CCA. Cimetidine, a histamine type 2 antagonist, is used to treat heartburn and peptic ulcer; however, data also indicates that cimetidine may contribute to growth inhibition and apoptosis induction in CCA in vitro and in vivo (57). Valproic acid is used to treat bipolar disorders and prevent migraine headaches; previous study identified that it may inhibit the growth of CCA cell lines (TFK-1, QBC939 and CCLP1) by inducing cell cycle arrest and promoting cell differentiation via induction of dendrite-like structures (58). The effects of each drug may be mediated by several molecular mechanisms. For example, valproic acid, an anti-epileptic drug, appears to act primarily by histone deacetylase inhibition, and not solely by inhibition of $C H E K 1, C T B P 1, B U B 1 B$, trophinin-associated protein, laminin subunit gamma 2, WDHD1, FAM $83 B$ and $F N D C 1$. For each of these drugs, further extensive studies, both in vitro and in vivo, are needed to confirm their effectiveness, molecular mechanisms and toxicity in the treatment of CCA.

Previous study (59) and the present data have demonstrated that lipid metabolism pathways may be significantly altered, and that lovastatin interacts with the dysregulated gene signatures. The lipid metabolism pathway may serve important roles in CCA growth and progression by downregulating the farnesoid $\mathrm{x}$ receptor and lipid metabolism pathways (59). Lovastatin is a medication used for lipid metabolic disorder, and blocks HMG-CoA reductase enzyme in cholesterol synthesis. This drug has been studied in vitro and in vivo and has been demonstrated to exert anticancer effects in CCA and enhancement of gefitinib-induced antiproliferation in resistant CCA (60-62).

Clofazimine is a drug used in the treatment of leprosy. It also has an anticancer effect and may be used for hepatocellular carcinoma (63). Certain antimalarial primaquines have been shown to block amino acid uptake in in vivo studies (64). From the present gene-drug interaction results, these drugs may have certain therapeutic roles in the context of CCA treatment; however further study is required.

COX-2 also serves an important role in CCA carcinogenesis, and is expressed at high levels in CCA tissue compared with non-tumorous adjacent tissue (65). Inhibition of COX-2 by nonsteroidal anti-inflammatory drugs, including peroxicam in combination with cisplatin, may trigger cell cycle regulation and apoptosis in different mesothelioma cell lines (MSTO-211H and NCI-H2452) (66).

The present results also revealed retinoic acid and caffeine to interact with gene signatures of the top most DEGs. Retinoic acid is categorized as a retinoid and has been studied for its therapeutic efficacy in numerous cancers. In CCA, cell migration and tumor invasion may be blocked by all trans-retinoic acid-incorporated glycol chitosan nanoparticles (67). Caffeine is a methylxanthine alkaloid related to the adenine and guanine bases. Previous reports demonstrated that caffeinated coffee consumption was associated with reduced risk of HCC and CCA $(68,69)$. However, since a molecular mechanism 
underlying the potential anticancer activity of caffeine is yet to be elucidated, it is probably best utilized as a supplement in daily diet. The present research is limited as the application of molecular data based on bioinformatics analysis may not be sufficient to predict the efficacy of potential targeted agents or protein inhibitors. Therefore, validation of the current data with case studies and additional functional downstream approach experiments is necessary.

In conclusion, the present study performed gene expression analysis, and based on the findings, assessed molecular pathways and drug interactions associated with DEG signatures in CCA. The present study may be developed to further examine drug repurposing and to search for additional anticancer activities among known pharmaceuticals. The results may provide a novel hypothesis regarding the mechanisms of non-antineoplastic drugs in cancer treatment. The data may be a useful resource for preclinical and clinical research on existing FDA-approved drugs into their potential use in CCA treatment.

\section{Acknowledgements}

The authors are thankful to Dr Janice M. Wongsurawat of the Chulabhorn Research Institute (Bangkok, Thailand), for proof-reading the manuscript.

\section{Funding}

The present study was supported by the Chulabhorn Graduate Institute and Chulabhorn Research Institute (Bangkok, Thailand).

\section{Availability of data and materials}

All data used and analyzed during this study are included in this published article.

\section{Authors' contributions}

SC performed data acquisition and data analysis and contributed to the drafting of the manuscript. TS was responsible for initiation, conception, experimental design and execution of the project and for critical revision of the manuscript. TU supervised the collection of anti-cancer drug information and contributed to the revision of the manuscript. YP supervised data analysis and contributed to the revision of the manuscript. JS supervised experimental design and critical revision of the manuscript. All authors read and approved the final manuscript.

\section{Ethics approval and consent to participate}

Not applicable.

\section{Consent for publication}

Not applicable.

\section{Competing interests}

The authors declare that they have no competing interests.

\section{References}

1. de Groen PC, Gores GJ, LaRusso NF, Gunderson LL and Nagorney DM: Biliary tract cancers. N Engl J Med 341: 1368-1378, 1999.

2. Wu T, Han C, Lunz JG III, Michalopoulos G, Shelhamer JH and Demetris AJ: Involvement of 85-kd cytosolic phospholipase A(2) and cyclooxygenase- 2 in the proliferation of human cholangiocarcinoma cells. Hepatology 36: 363-373, 2002.

3. Patel T: Worldwide trends in mortality from biliary tract malignancies. BMC Cancer 2: 10, 2002.

4. Shaib YH, Davila JA, McGlynn K and El-Serag HB: Rising incidence of intrahepatic cholangiocarcinoma in the United States: A true increase? J Hepatol 40: 472-477, 2004.

5. Nakeeb A, Pitt HA, Sohn TA, Coleman J, Abrams RA, Piantadosi S, Hruban RH, Lillemoe KD, Yeo CJ and Cameron JL: Cholangiocarcinoma. A spectrum of intrahepatic, perihilar, and distal tumors. Ann Surg 224: 463-473, 1996.

6. Patel T: Increasing incidence and mortality of primary intrahepatic cholangiocarcinoma in the United States. Hepatology 33: 1353-1357, 2001.

7. Sahu S and Sun W: Targeted therapy in biliary tract cancers-current limitations and potentials in the future. J Gastrointest Oncol 8: 324-336, 2017.

8. Ohashi K, Nakajima Y, Kanehiro H, Tsutsumi M, Taki J, Aomatsu Y, Yoshimura A, Ko S, Kin T, Yagura K, et al: Ki-ras mutations and p53 protein expressions in intrahepatic cholangiocarcinomas: Relation to gross tumor morphology. Gastroenterology 109: 1612-1617, 1995.

9. Furubo S, Harada K, Shimonishi T, Katayanagi K, Tsui W and Nakanuma Y: Protein expression and genetic alterations of p53 and ras in intrahepatic cholangiocarcinoma. Histopathology 35: 230-240, 1999.

10. Tannapfel A, Sommerer F, Benicke M, Katalinic A, Uhlmann D, Witzigmann $\mathrm{H}$, Hauss J and Wittekind C: Mutations of the BRAF gene in cholangiocarcinoma but not in hepatocellular carcinoma. Gut 52: 706-712, 2003.

11. Xu X, Kobayashi S, Qiao W, Li C, Xiao C, Radaeva S, Stiles B, Wang RH, Ohara N, Yoshino T, et al: Induction of intrahepatic cholangiocellular carcinoma by liver-specific disruption of Smad4 and Pten in mice. J Clin Invest 116: 1843-1852, 2006.

12. Endo K, Yoon BI, Pairojkul C, Demetris AJ and Sirica AE: ERBB-2 overexpression and cyclooxygenase-2 up-regulation in human cholangiocarcinoma and risk conditions. Hepatology 36 : 439-450, 2002

13. Sugawara H, Yasoshima M, Katayanagi K, Kono N, Watanabe Y, Harada K and Nakanuma Y: Relationship between interleukin-6 and proliferation and differentiation in cholangiocarcinoma. Histopathology 33: 145-153, 1998.

14. Chabner BA: Early accelerated approval for highly targeted cancer drugs. N Engl J Med 364: 1087-1089, 2011.

15. Wu T, Leng J, Han C and Demetris AJ: The cyclooxygenase-2 inhibitor celecoxib blocks phosphorylation of Akt and induces apoptosis in human cholangiocarcinoma cells. Mol Cancer Ther 3: 299-307, 2004.

16. Peng YC, Lin CL, Hsu WY, Chang CS, Yeh HZ, Tung CF, Wu YL, Sung FC and Kao CH: Statins are associated with a reduced risk of cholangiocarcinoma: A population-based case-control study. Br J Clin Pharmacol 80: 755-761, 2015.

17. Andersen JB, Spee B, Blechacz BR, Avital I, Komuta M, Barbour A, Conner EA, Gillen MC, Roskams T, Roberts LR, et al: Genomic and genetic characterization of cholangiocarcinoma identifies therapeutic targets for tyrosine kinase inhibitors. Gastroenterology 142: 1021-1031e15, 2012.

18. Ashburner M, Ball CA, Blake JA, Botstein D, Butler H, Cherry JM, Davis AP, Dolinski K, Dwight SS, Eppig JT, et al; The Gene Ontology Consortium: Gene ontology: Tool for the unification of biology. Nat Genet 25: 25-29, 2000.

19. Huang W, Sherman BT and Lempicki RA: Bioinformatics enrichment tools: Paths toward the comprehensive functional analysis of large gene lists. Nucleic Acids Res 37: 1-13, 2009.

20. Kanehisa M and Goto S: KEGG: Kyoto encyclopedia of genes and genomes. Nucleic Acids Res 28: 27-30, 2000.

21. Szklarczyk D, Franceschini A, Kuhn M, Simonovic M, Roth A, Minguez P, Doerks T, Stark M, Muller J, Bork P, et al: The STRING database in 2011: Functional interaction networks of proteins, globally integrated and scored. Nucleic Acids Res 39 (Database): D561-D568, 2011. 
22. von Mering C, Jensen LJ, Snel B, Hooper SD, Krupp M, Foglierini sM, Jouffre N, Huynen MA and Bork P: STRING: Known and predicted protein-protein associations, integrated and transferred across organisms. Nucleic Acids Res 33: D433-D437, 2005.

23. Kandoth C, Schultz N, Cherniack AD, Akbani R, Liu Y, Shen H, Robertson AG, Pashtan I, Shen R, Benz CC, et al; Cancer Genome Atlas Research Network: Integrated genomic characterization of endometrial carcinoma. Nature 497: 67-73, 2013.

24. Gao J, Aksoy BA, Dogrusoz U, Dresdner G, Gross B, Sumer SO, Sun Y, Jacobsen A, Sinha R, Larsson E, et al: Integrative analysis of complex cancer genomics and clinical profiles using the cBioPortal. Sci Signal 6: pl1, 2013

25. Cerami E, Gao J, Dogrusoz U, Gross BE, Sumer SO, Aksoy BA, Jacobsen A, Byrne CJ, Heuer ML, Larsson E, et al: The cBio cancer genomics portal: An open platform for exploring multidimensional cancer genomics data. Cancer Discov 2: 401-404 2012.

26. Yoo M, Shin J, Kim J, Ryall KA, Lee K, Lee S, Jeon M, Kang J and Tan AC: DSigDB: Drug signatures database for gene set analysis. Bioinformatics 31: 3069-3071, 2015.

27. Lamb J, Crawford ED, Peck D, Modell JW, Blat IC, Wrobel MJ, Lerner J, Brunet JP, Subramanian A, Ross KN, et al: The Connectivity Map: Using gene-expression signatures to connect smal molecules, genes, and disease. Science 313: 1929-1935, 2006

28. Qin C, Zhang C, Zhu F, Xu F, Chen SY, Zhang P, Li YH, Yang SY, Wei YQ, Tao L, et al: Therapeutic target database update 2014: A resource for targeted therapeutics. Nucleic Acids Res 42 (D1): D1118-D1123, 2014.

29. Davis AP, Wiegers TC, Roberts PM, King BL, Lay JM, LennonHopkins K, Sciaky D, Johnson R, Keating H, Greene N, et al: A CTD-Pfizer collaboration: Manual curation of 88,000 scientific articles text mined for drug-disease and drug-phenotype interactions. Database (Oxford) 2013: bat080, 2013.

30. Silsirivanit A, Sawanyawisuth K, Riggins GJ and Wongkham C: Cancer biomarker discovery for cholangiocarcinoma: The highthroughput approaches. J Hepatobiliary Pancreat Sci 21: 388-396, 2014.

31. Massey AJ: Tumour growth environment modulates Chk1 signalling pathways and Chk1 inhibitor sensitivity. Sci Rep 6 : $35874,2016$.

32. Yang L, Feng S and Yang Y: Identification of transcription factors (TFs) and targets involved in the cholangiocarcinoma (CCA) by integrated analysis. Cancer Gene Ther 23: 439-445, 2016.

33. Seubwai W, Kraiklang R, Wongkham C and Wongkham S: Hypoxia enhances aggressiveness of cholangiocarcinoma cells. Asian Pac J Cancer Prev 13 (Suppl): 53-58, 2012

34. Borad MJ, Champion MD, Egan JB, Liang WS, Fonseca R, Bryce AH, McCullough AE, Barrett MT, Hunt K, Patel MD, et al: Integrated genomic characterization reveals novel, therapeutically relevant drug targets in FGFR and EGFR pathways in sporadic intrahepatic cholangiocarcinoma. PLoS Genet 10: e1004135, 2014.

35. Tongtawee T, Kaewpitoon SJ, Loyd R, Chanvitan S, Leelawat K, Praditpol N, Jujinda S and Kaewpitoon N: High expression of matrix metalloproteinase-11 indicates poor prognosis in human cholangiocarcinoma. Asian Pac J Cancer Prev 16: 3697-3701, 2015.

36. Severino FE, Hasimoto CN, Rodrigues MAM, Llanos JC and Reis PP: Integrative analysis of transcriptome and microRNome profiles in cholangiocarcinoma. J Cancer Sci Ther 09: 580-588, 2017

37. Navaneethan U, Lourdusamy V, Gk Venkatesh P, Willard B, Sanaka MR and Parsi MA: Bile proteomics for differentiation of malignant from benign biliary strictures: A pilot study. Gastroenterol Rep (Oxf) 3: 136-143, 2015.

38. Huang QX, Cui JY, Ma H, Jia XM, Huang FL and Jiang LX Screening of potential biomarkers for cholangiocarcinoma by integrated analysis of microarray data sets. Cancer Gene Ther 23 48-53, 2016.

39. Smith J, Tho ML, Xu N and Gillespie DA: The ATM-Chk2 and ATR-Chk1 pathways in DNA damage signaling and cancer. Adv Cancer Res: 73-112, 2010

40. Bartek J and Lukas J: Chk1 and Chk2 kinases in checkpoint control and cancer. Cancer Cell 3: 421-429, 2003.

41. Kuroki T, Tomioka T, Tajima Y, Inoue K, Ikematsu Y, Ichinose K, Furui J and Kanematsu T: Detection of the pancreas-specific gene in the peripheral blood of patients with pancreatic carcinoma. $\mathrm{Br}$ J Cancer 81: 350-353, 1999.

42. Nath A and Chan C: Genetic alterations in fatty acid transport and metabolism genes are associated with metastatic progression and poor prognosis of human cancers. Sci Rep 6: 18669, 2016
43. Chen Y and Li P: Fatty acid metabolism and cancer development Sci Bull (Beijing) 61: 1473-1479, 2016.

44. Sung J, Wang Y, Chandrasekaran S, Witten DM and Price ND Molecular signatures from omics data: From chaos to consensus. Biotechnol J 7: 946-957, 2012.

45. Zhu P, Aliabadi HM, Uluda $\breve{g} \mathrm{H}$ and Han J: Identification of potential drug targets in cancer signaling pathways using stochastic logical models. Sci Rep 6: 23078, 2016.

46. Mann BS, Johnson JR, He K, Sridhara R, Abraham S, Booth BP, Verbois L, Morse DE, Jee JM, Pope S, et al: Vorinostat for treatment of cutaneous manifestations of advanced primary cutaneous T-cell lymphoma. Clin Cancer Res 13: 2318-2322, 2007.

47. Audeh MW, Carmichael J, Penson RT, Friedlander M, Powell B, Bell-McGuinn KM, Scott C, Weitzel JN, Oaknin A, Loman N, et al: Oral poly(ADP-ribose) polymerase inhibitor olaparib in patients with BRCA1 or BRCA2 mutations and recurrent ovarian cancer: A proof-of-concept trial. Lancet 376: 245-251, 2010

48. Wood L: Sunitinib malate for the treatment of renal cell carcinoma. Expert Opin Pharmacother 13: 1323-1336, 2012

49. Roskoski R Jr: RAF protein-serine/threonine kinases: Structure and regulation. Biochem Biophys Res Commun 399: 313-317, 2010.

50. Ma J, Shi J, Zhao D, Cheng L, Wang W, Li F, Jiang X and Jiang H: Raf kinase inhibitor protein inhibits cholangiocarcinoma cell metastasis by downregulating matrix metalloproteinase 9 and upregulating tissue inhibitor of metalloproteinase 4 expression. Oncol Lett 9: 15-24, 2015.

51. Dreyer C, Sablin MP, Bouattour M, Neuzillet C, Ronot M, Dokmak S, Belghiti J, Guedj N, Paradis V, Raymond E, et al: Disease control with sunitinib in advanced intrahepatic cholangiocarcinoma resistant to gemcitabine-oxaliplatin chemotherapy. World J Hepatol 7: 910-915, 2015.

52. Eckmann KR, Patel DK, Landgraf A, Slade JH, Lin E, Kaur H, Loyer E, Weatherly JM and Javle M: Chemotherapy outcomes for the treatment of unresectable intrahepatic and hilar cholangiocarcinoma: A retrospective analysis. Gastrointest Cancer Res 4: 155-160, 2011.

53. Valle J, Wasan H, Palmer DH, Cunningham D, Anthoney A, Maraveyas A, Madhusudan S, Iveson T, Hughes S, Pereira SP, et al; ABC-02 Trial Investigators: Cisplatin plus gemcitabine versus gemcitabine for biliary tract cancer. N Engl J Med 362: 1273-1281, 2010

54. Merla A, Liu KG and Rajdev L: Targeted therapy in biliary tract cancers. Curr Treat Options Oncol 16: 48, 2015.

55. Ruzzenente A, Fassan M, Conci S, Simbolo M, Lawlor RT, Pedrazzani C, Capelli P, D'Onofrio M, Iacono C, Scarpa A, et al: Cholangiocarcinoma heterogeneity revealed by multigene mutational profiling: Clinical and prognostic relevance in surgically resected patients. Ann Surg Oncol 23: 1699-1707, 2016.

56. Brandi G, Farioli A, Astolfi A, Biasco G and Tavolari S: Genetic heterogeneity in cholangiocarcinoma: A major challenge for targeted therapies. Oncotarget 6: 14744-14753, 2015.

57. Dana P, Vaeteewoottacharn K, Kariya R, Matsuda K, Wongkham S and Okada S: Repurposing cimetidine for cholangiocarcinoma: Antitumor effects in vitro and in vivo. Oncol Lett 13: 1432-1436, 2017.

58. Wang B, Yang R, Wu Y, Li H, Hu Z, Chen Y and Zou S: Sodium valproate inhibits the growth of human cholangiocarcinoma in vitro and in vivo. Gastroenterol Res Pract 2013: 374593, 2013.

59. Kwee SA, Okimoto GS, Chan OTM, Tiirikainen M and Wong LL: Metabolic characteristics distinguishing intrahepatic cholangiocarcinoma: A negative pilot study of (18)F-fluorocholine PET/CT clarified by transcriptomic analysis. Am J Nucl Med Mol Imaging 6: 73-83, 2016.

60. Yang SH, Lin HY, Chang VHS, Chen CC, Liu YR, Wang J, Zhang K, Jiang X and Yen Y: Lovastatin overcomes gefitinib resistance through TNF- $\alpha$ signaling in human cholangiocarcinomas with different LKB1 statuses in vitro and in vivo. Oncotarget 6: 23857-23873, 2015.

61. Yang SH, Lin HY, Changou CA, Chen $\mathrm{CH}$, Liu YR, Wang J, Jiang $X$, Luh F and Yen Y: Integrin $\beta 3$ and LKB1 are independently involved in the inhibition of proliferation by lovastatin in human intrahepatic cholangiocarcinoma. Oncotarget 7: 362-373, 2016.

62. Kim BB, Kim M and Park JB: The effects of lovastatin on the morphology, cell viability and differentiation of stem cells derived from gingiva. Biomed Res (Aligarh) 28: 4922-4927, 2017.

63. Ruff P, Chasen MR, Long JEH and van Rensburg CE: A phase II study of oral clofazimine in unresectable and metastatic hepatocellular carcinoma. Ann Oncol 9: 217-219, 1998.

64. Das AK: Anticancer effect of antimalarial artemisinin compounds. Ann Med Health Sci Res 5: 93-102, 2015. 
65. Chariyalertsak S, Sirikulchayanonta V, Mayer D, KoppSchneider A, Fürstenberger G, Marks F and Müller-Decker K: Aberrant cyclooxygenase isozyme expression in human intrahepatic cholangiocarcinoma. Gut 48: 80-86, 2001.

66. Verdina A, Cardillo I, Nebbioso A, Galati R, Menegozzo S, Altucci L, Sacchi A and Baldi A: Molecular analysis of the effects of piroxicam and cisplatin on mesothelioma cells growth and viability. J Transl Med 6: 27, 2008.

67. Chung KD, Jeong YI, Chung CW, Kim DH and Kang DH: Anti-tumor activity of all-trans retinoic acid-incorporated glycol chitosan nanoparticles against HuCC-T1 human cholangiocarcinoma cells. Int J Pharm 422: 454-461, 2012.

68. Petrick JL, Freedman ND, Graubard BI, Sahasrabuddhe VV, Lai GY, Alavanja MC, Beane-Freeman LE, Boggs DA, Buring JE, Chan AT, et al: Coffee consumption and risk of hepatocellular carcinoma and intrahepatic cholangiocarcinoma by sex: The liver cancer pooling project. Cancer Epidemiol Biomarkers Prev 24: $1398-1406,2015$
69. Kennedy OJ, Roderick P, Buchanan R, Fallowfield JA, Hayes PC and Parkes J: Coffee, including caffeinated and decaffeinated coffee, and the risk of hepatocellular carcinoma: A systematic review and dose-response meta-analysis. BMJ Open 7: e013739, 2017.

This work is licensed under a Creative Commons Attribution-NonCommercial-NoDerivatives 4.0 International (CC BY-NC-ND 4.0) License. 